\title{
Disability, Girlhood, and Vulnerability in Transnational Contexts
}

\author{
Nirmala Erevelles and Xuan Thuy Nguyen
}

\section{$\cos 80$}

When we first proposed this special issue on "Disability and Girlhood: Transnational Perspectives," we had not yet realized how the urgency in the global humanitarian crises that has escalated in intensity and scope of violence in recent months would demand our thoughtful attention. These crises, the outcomes of social protest, wars, and genocidal acts in many parts of the world for over a decade, punctuated by the Paris bombings of November 2015 that took the lives of 130 innocent citizens; the widespread displacement of 4 million Syrian refugees from their homeland; the increased militarization at the borders of the European Union and the United States; and the environmental impact of this war of terror on the daily survival of disabled and non-disabled people around the globe continue unabated. On the internet, photographic images of women and children with disabilities (and girls in particular) serve as the very embodiment of vulnerability in competition with thousands of other images of suffering (see for instance, Human Rights Watch 2012) vying for the attention of an impatient and fickle global audience (Goggin 2009; Kim 2011). In these images, disability, seen to be synonymous with vulnerability becomes simultaneously hypervisible in its ability to trigger an affective response and hyper-invisible when inspiring an emancipatory response to the material consequences of actually living with a disability.

This special volume includes contributions from academics, activists, and service providers who engage with the intersectional domains of disability, gender, and humanitarian praxis. While vulnerability was not even mentioned in the call for submissions, we found that the affective politics of vulnerability appears as an "absent presence" (Ferri and Connor 2010: 106) in every submission included here. Vulnerability, when we use the term to refer to an individual or a group, makes "specific claims about differential power, as well as ... acknowledge[ing] the speaker's own feelings of the 
capacity to be wounded by others and to wound other bodies" (Kim 2014: 146). This affective politics of vulnerability can therefore manipulate that which "is visually and psychically contained in the body of an Other-here, a girl child with a disability" (139). Take for example, how, in Todd's article, the phenomenon of transnational child adoption draws on the sensationalized disabled body (thus evoking the affective politics of vulnerability) for the pleasurable consumption by a non-disabled audience. On pondering the spectral presence of vulnerability in this volume, we realized that both girlhood studies and disability studies are compelled, both intellectually and materially, to grapple with the political implications of how girls and disabled people have always been constituted historically as vulnerable populations. Associations with vulnerability invoke the contradictory combination of peril and promise. For example, in neoliberal contexts that privilege resilient, independent, can-do girls, the impetus to reject vulnerability (read non-white, female, disabled, queer) underline several conceptual contradictions at the intersections of disability studies and girlhood studies (Gonick 2006; Kim 2014).

The focus of this special issue is on building more enduring conceptual alliances between disability studies and girlhood studies in favor of transdisciplinary analyses. To do so we have drawn on the work of scholars in both areas, recognizing the potential in engaging and disrupting knowledge bases that have traditionally been separated by disciplinary boundaries. Responding to Erevelles and Mutua's (2005) argument that within girlhood studies, disability trumps other social identities, Stienstra, for example, has asked,

Why does disability as a problem or lack figure so prominently in the stories of girls with disabilities? Does disability substantively and negatively alter all experiences of girls? How do experiences of disability interact with global location, minority culture or being Indigenous for girls? (2015: 55).

Here, Stienstra recognizes the conceptual power of disability to disrupt even the radical politics of difference espoused by girlhood studies. In this issue, our serendipitous recognition of vulnerability as an absent presence in the intersectional analyses of disability and girlhood has encouraged us to make some cautious claims. By bringing girlhood studies and disability studies together in the communal space of this journal, we are insistent that disability is neither an addition to the overcrowded field that constitutes the politics of difference, nor does it serve to merely nuance the complex terrain of intersectional politics (Erevelles 2011). Rather, we argue that disability serves as a disruptive force in the field of girlhood studies and does so around the affective politics of vulnerability. We argue that vulnerability for disabled 
subjectivity (unlike for other non-disabled bodies) is a material reality that may be central to the framing of disability identity even when disabled bodies refuse this vulnerability (see, for example, the review of the film, Margarita with a Straw in this volume).

Each of the articles in this issue alludes to the affective politics of vulnerability at the intersecting sites of disability studies and girlhood studies, while exploring how disability and girlhood matter in transnational contexts. We employ the concept of transnationalism to

\begin{abstract}
explore what the category of the transnational illuminates - the work it does in particular feminist contexts - the relation of the transnational to colonial, neocolonial, and imperial histories and practices on different geographical scales, and finally ... to analyze the specific material and ideological practices that constitute the transnational at this historical juncture and in the ... sites we ourselves occupy (Alexander and Mohanty 2010: 24).
\end{abstract}

We hope that the articles, through engaging with hierarchies of power in diverse contexts, have the potential to negate forms of domination by connecting the stories of disabled girls within and across geographical borders. To do this work, the articles use a range of methodologies that include cultural critique, literary criticism, and empirical research. These diverse approaches are useful for constructing alternative sites in which disability and girlhood are re-theorized in response to different hierarchies of power within discursive spaces like literary texts and popular culture, socio-political spaces such as war zones, conflict and post-conflict contexts, and geographical spaces that have been shaped by colonialism, neoliberalism, and transnational capitalism. It is for these reasons that we underscore the timeliness of this volume for academics, activists, and humanitarian workers as a way of tackling existing forms of exclusion based on commonly held perceptions of vulnerability attributed to disability and girlhood transnationally.

We invite our readers to enter into a transnational dialogue on disability and girlhood by considering the following questions: How do particular definitions of girlhood include/ exclude disabled bodies? What discursive constructions of girlhood and disability are (dis)enabled within diverse social, political, legal, and economic contexts? What are the implications of these constructions for disability and girlhood transnationally? How do oppressive practices of colonialism, neoliberalism, transnational capitalism, racism, and heteropatriarchy constitute disability and girlhood as vulnerable? What are the social, political, and conceptual implications of associating vulnerability with disability and girlhood for transformative praxis? Keeping these questions in mind, in the next section we discuss the conceptual challenge that 
vulnerability poses to both disability studies and girlhood studies. We then trace the emergence of disability and girlhood in human rights-based discourses to illuminate the contested framing of girls with disabilities transnationally and the material effects of these discourses on their well-being. We conclude by reflecting on the conceptual challenges posed in theorizing girlhood from the critical standpoint of disability studies while thinking with and through vulnerability.

\section{Disability and Girlhood: Vulnerability and its Discontents}

In an essay entitled, "The Spectre of Vulnerability and Disabled Bodies in Protest," Eunjung Kim foregrounds how discourses of vulnerability proliferate in both humanitarian efforts and social justice movements by making visible "wounded bodies and the ever-present threat of harm" (2014:137). Kim's essay opens with a close reading of the Afghan film, Kandahar that features several scenes portraying bodies disabled by war. Remarking on these scenes in the film, Kim describes how "[d]isability is perceived as an anomalous incapacity, inviting harm or providing causes of harm, and as located within an individual body isolated from the social contexts that facilitate violence" (138). Given that there is a propensity for disability to appear habitually in social narratives that foreground vulnerability, especially in contexts located within the Global South, Kim asks,

What would happen if one compares the view of disability as evidence of social injustice and global struggle and the view of disability as evidence of diversity and belonging? Are the two perspectives incompatible? How does looking at disability as representing broader social contexts limit the understanding of everyday lives of disabled people vis-a-vis nondisabled people in non-Western societies? Is the disabled body constructed as tragic consequence of injustice specific to the non-Western world and positioned in relation to disability constructed as diversity and culture in the Western world? When bodies are wounded by violence, at what point does this consequential body of harm become a being entitled to resources and accommodation beyond the grief associated with loss of an able body? (140-141).

These questions situate disability in a complicated relationship with the affective politics of vulnerability, where disability, commonly conceived of as "negative ontology," embodies what a body "ought not [to] be" (Titchkosky 2005: 663). But disability as embodied vulnerability has come to represent more than "a limit without possibility" (657). In fact, humanitarian organizations and social justice movements rely on "disempowering 
images of racialized, gendered, and disabled non-Western bodies as needing help, an approach that feeds on the assumption that disability-particularly outside of a Western context - in and of itself is direct evidence of tragic harm, injustice, and deprivation" (Kim 2014: 140). Thus, disability, conceived of simultaneously as dangerous threat and pitiable need, represents a vulnerability "attached to certain medical and legal categories of identity" (141) from which social movements committed to anti-racist, feminist, queer, and/or class struggle seek to distance themselves.

The move to distance oneself from associating with vulnerability also marks a similar historical trajectory in girlhood studies. Scholars in girlhood studies have observed how the initial invisibility of girls in critical social inquiry transformed uneasily into discourses portraying girls in perpetual crisis that, in turn, inspired the counter discourses of Girl Power (Aopola, Gonick, and Harris 2005; Gilmore and Marshall 2010). Girl Power celebrated "the fierce and aggressive potential of girls as well as the reconstitution of girl culture as a positive force embracing self-expression through fashion, attitude, and a Do-It-Yourself (DIY) approach to cultural production" (Gonick 2006: 6). Thus, Girl Power became the platform for refusing vulnerability as an integral characteristic of girlhood in an effort to "approach girls not as problems-to-be-solved or subjects-to-be-rescued, but as agents who face systemic barriers to their own agency and autonomy, [so that] we can begin to stop linking them to crisis constructions that denigrate their subjectivities and experiences...." (Rentschler and Mitchell 2014: 3).

The discourses of Girl Power soon drew criticism. Gonick, for instance, has critiqued the neoliberal ideologies espoused by Girl Power and the Girlsin-Crisis discourses, claiming that while the former represents "the idealized form of the self-determining individual ... the latter [personifies] an anxiety about those who are unsuccessful in producing themselves in this way" (2006: 2). Ferri and Connor (2010), among others, were also critical that the focus on individual girls' personal circumstances and personal traits directed attention away from the structural conditions of inequality that locate girls along differentiated hierarchies of power in local and transnational contexts. Thus, scholars have now conceived of girlhood "as a site of contest, with gender performativity as a site of contested meanings, and where sometimes embodying the norm is linked to the very question of survival" (Gannon and Gonick 2014: 31).

Implicit in some arguments that support and/or critique the discourses of Girl Power lies the anxiety of being unable to meet the demands of normative (girl) subjectivity resulting in a rejection of vulnerability, and there- 
fore, disability. In this scenario, disability trumps all other difference and as a result, girlhood studies has historically had a very limited engagement with disability studies (Erevelles and Mutua 2004; Stienstra 2015). This distancing from vulnerability is not peculiar to girlhood studies. Rather, every other category of difference, namely race, gender, and sexuality, also eschews the affective politics of vulnerability as embodied in disabled (girl) citizens (Erevelles 2011). Moreover, even if few theorists in girlhood studies reject normativity and embrace the vulnerable (girl) subject, they may fail to observe the nuanced differences between "universal and identitarian perspectives" (Kim 2014: 144). Citing Judith Butler, Kim explains that while the universal perspective observes vulnerability as an essential part of the human condition, an identitarian perspective regards groups as vulnerable if their needs are thwarted on account of social and economic violence. Here, again, vulnerability is understood as an attribute that can be freely chosen by or forcibly thrust upon (girl) subjects.

However, for disabled girls, vulnerability is not discursive but material. Disabled girls live interdependent lives enmeshed within complex relations of care. Their body-mind differences support physical, intellectual, and emotional vulnerabilities in varying social, cultural, and economic contexts. Because disabled girls are assumed to be different from, and inferior to those who are seen to comply with the criteria of so-called normative girlhood, they are perceived as lacking autonomy and agency (Jennings 2013). For example, Jennings points out that girls with developmental disabilities, or those who live with severe impairments are usually treated by the law as though they lack full personhood. This misperception leads to a deadly vulnerability in which, according to Jennings, "the line between life and death is not clearly drawn ... [such that] they are being positioned legally and ethically towards the end of a continuum" (71). Additionally, in recent years, there have been several cases both in the US and Canada where parents have received minimal to no sentencing after having murdered their disabled daughters (the murder of Tracy Latimer in Canada being the most famous example) (Jennings 2013). This has occurred in a context in which disabled girls are presumed to be unable to give or withhold consent for medical treatment, personal care, sexual choice, as well as the claim to motherhood, under the guise of protecting their vulnerable selves (Titchkosky 2005; Jennings 2013; see also the case of Ashley X, a 9-year-old girl from Seattle, Washington discussed in Erevelles's review of Ghai's book in this volume). Similar cases like those of Eve in Canada, Jeanette in England, and Marion in Australia (Rioux and Patton 2011) have undermined the recognition of the person- 
hood of disabled girls under the law and have led to the perpetuation of their "dis-citizenship" (Pothier and Delvin 2006:17), and all this has been justified on the grounds of protecting their vulnerable disabled bodies.

In these examples, unlike other communities of difference, disabled people (and girls, in this instance) cannot easily reject the vulnerability that forms an intimate aspect of disability identity. In fact, many in the disability community may not necessarily regard vulnerability as a negative attribute related to their personhood (see Ghai's book, Disability in India, reviewed in this volume). It is in this context that disability studies scholar Michelle Jarman (2005) argues for the association of disability with radical vulnerability. Kim, drawing on Jarman, describes radical vulnerability as the ability to

forge cross-identity, cross-cultural alliances that refuse the inscription of Western values upon third world bodies .... If we think of disability in terms of radical vulnerability, we insist not only upon a critical reading of the figure presented as innately vulnerable, but more importantly, upon exposing the concealed fears and desires mirrored by the discursive drive to exclude, efface, or eradicate... . Radical vulnerability is a transgressive point of departure for exposing the divides mapped onto an uneven geography and the privilege hidden beneath the claim of universal vulnerability (2014: 145).

Even while not explicitly stated, the articles in this volume refuse "the purifying eradication of physiological and aesthetic difference" (Kim 2014: 145) so as to offer, instead, examples of radical vulnerability that speak back against normative discourses of girlhood. Whether it is writing against ablenationalism in the brand American Girls (Schalk), or challenging US exceptionalism usually attributed to being a counterpoint to vulnerability (Todd), or embracing the queer transgressions of the freak (Sperling), or engaging the contested spaces of inclusion/exclusion occupied by disabled girls (Nguyen as well as Smith-D'Arezzo and Holc), an articulation of radical vulnerability implicitly pervades this volume. We, therefore, draw the attention of our readers to this absent presence of vulnerability in this analytical context where disability and girlhood intersect.

\section{Girls with Disabilities and Rights-based Discourses}

Humanitarian organizations draw on discourses of vulnerability when they are using a rights-based approach in relation to disabled girls (Jarman 2005; Kim 2011). These discourses follow "two trends: 'shock effect appeals' focusing on the image of suffering, and 'positive image appeals' focusing on 'the sufferer's agency and dignity' in the context of people in poverty." Both trends conceive 
of disability as "undesirable suffering" (Kim 2011: 95) and, in so doing, ironically maintain the very victim status that they seek to relieve through humanitarian actions (Kim 2011; Nguyen 2015). While this framing exists in tension with the charity model (Pinto 2011), one that elicits pity when cure is unattainable, many human rights approaches and discourses (for example, Human Rights Watch 2012; Ortoleva and Lewis 2012; DAWN-RAPH, ${ }^{1}$ n.p.) have continued to maintain the representation of disabled people as victims of state power that has failed to protect their rights. A critical engagement with radical vulnerability, we argue, can enable disabled girls to construct counter discourses that support democratizing approaches to theory and praxis at the intersections of disability and girlhood. In this section, we, therefore, trace the historical emergence of disabled girlhood in the context of global imperatives directed towards girls' education and disability rights framed within UNESCO's Education for All (EFA) framework and the United Nations' Convention on the Rights of Persons with Disabilities (UNCRPD). Our goal here is to consider the ways in which these rights-based discourses articulated in the context of international development and directed towards the mainstreaming of disabled women and girls draw on the discourse of vulnerability.

In May 2013, the United Nations Girls' Education Initiative (UNGEI), in the Asia and Pacific (2013) newsletter, ${ }^{2}$ called for public institutions to address disability, girlhood, and education in the following statement.

Education for all children cannot be achieved without the inclusion of girls and boys with disabilities. Ensuring effective policies and programs will require investment in focused research and in depth analysis to examine how different children are affected and how areas of marginalization intersect. The girl child with a disability warrants attention in education discourse, policy and practice (n.p.).

These institutional actions have demonstrated a paradigm shift in global governance. These actions include, for instance, the mainstreaming of disability issues into policies and programming under the auspices of UNCRPD. The institutional effort to include disability in education and humanitarian frameworks, such as the Global Partnership on Children with Disabilities (n.d.), ${ }^{3}$ the Global Partnership in Education (n.d.), ${ }^{4}$ and the Sustainable Development Goals framework (Rehabilitation International n.d.) $)^{5}$ manifests the global restructuring of policy and law in ways that recognize the exclusion of disabled children. However, notwithstanding this imperative to include disabled children in institutional programming, Harilyn Rousso writes,

The most formidable barrier to educational equity for girls with disabilities may be their invisibility. They are not on the radar screen of either those committed to educational equity for girls, because as a rule, disability is not included in their 
work, or those committed to educational equity for children with disabilities, because with similar oversight, gender is not considered (2003: 2).

Recognizing this inadequacy, UNCRPD (2006) has been instrumental in ensuring that girls with disabilities be included in the global agenda by mobilizing benevolent discourses of protection in attempts to reconstruct disabled girls as rights-holders in the face of intensified forms of exclusion in transnational contexts. However, a critical reading of UNCRPD further illuminates some theoretical challenges of the United Nations' human rightsbased approach for disabled girls. Preamble (q) and Article 6 highlight a recognition of different forms of discrimination facing women and girls with disabilities such as violence and discrimination. However, disabled girls and boys have been almost absent from its remaining text. For example, Article 7 of UNCRPD guarantees "the full enjoyment by children with disabilities of all human rights and fundamental freedoms" and must be granted "in accordance with their age and maturity" (United Nations 2006: n.p.). Unfortunately, while an understanding of the social constructions of childhood is important for understanding the meanings of disability (Beazley and Williams 2014), UNCRPD has naturalized childhood experiences through its universal constructions of the child, and in so doing, has treated girls with disabilities as an invisible Other.

Transnational disabled activists working in the context of human rights and international development have demanded the establishment of legal provisions and specific programs that address the institutional exclusion of disabled women and girls in social, political, and legal domains (Frohmader and Meekosha 2012; Ortoleva and Lewis 2012). Ortoleva and Lewis argue, for example, that " $[\mathrm{o}]$ ne of the most obvious and egregious barriers to access to justice for women [and girls] with disabilities is the physical barriers to courthouses and other institutions of the justice system" (2012: 59). Indeed, despite the efforts of UNGEI to address the educational needs of disabled girls, their invisibility in international human rights discourses continues to exacerbate the exclusion of disabled girls from the justice system. These gaps in knowledge are further increased by competing ideologies that emerge from the specific socio-historical conditions constituting the contentious relationship between the Global South and the Global North, and prompt the following questions: Who are girls with disabilities? What meanings are attributed to this label? How does the human rights approach to disability address the disadvantages disabled girls experience in their daily lives? And, finally, how does the affective politics of vulnerability deployed by this rightsbased approach to disability affect disabled girls? 
We argue here that vulnerability is the organizing concept that influences the rights-based approach to disabled girls in transnational humanitarian organizations. Take, for example, the debates around the terminology, "girls with disabilities." As Elizabeth Hastings, an Australian Disability Discrimination Commissioner from 1993 to 1997 argues,

There is often an atmosphere of blame, or of tragedy, for which the girl who has a disability may feel responsible. She may be isolated at home, lonely, unable to visit friends or even venture outside the front door without assistance (1997: n.p.).

Mindful of the absence of girls with disabilities in the Australian National Action Plan for the Education of Girls, Hastings forcefully argues that this policy excludes "a girl who has a disability" based on the assumption that she is not a girl in the first place, but rather, a "disabled" (n.p.). This argument separates disability from girlhood through its framing of disability as impairment (a negative physical and/or mental deficit according to the medical model) rather than seeing disability and girlhood as socially and politically constituted subjectivities (as in the social model). Following this logic, several transnational humanitarian organizations, eschewing the focus on the vulnerability of disability, prefer the term "girls with disabilities" rather than "disabled girls" (see Pearce et al. and De Lange et al. in this volume).

Another space in which vulnerability is synonymous with disability appears in the rights-based approach to disabled girlhood in its invocation of benevolent discourses of protection. For example, Leonard Cheshire (2014), a founding organization in disability and development in the United Kingdom, has drawn on UNCRPD to associate this individualizing approach to disability with the failure of states to offer adequate human rights protection for women and girls with disabilities in development interventions. What, then, are the political implications of framing disability, human rights, and gender equality within discourses of vulnerability and how has this framing shaped the actual lives of disabled girls in the relational contexts of the Global South and the Global North? Further, how have contested meanings of vulnerability, disability, and girlhood shaped the realities of inclusion and exclusion in transnational contexts?

\section{Overview of this Special Issue: Diverse Methodologies/ Radical Perspectives}

This special issue writes against prevailing ideologies that extend "beyond the grief associated with loss of an able body" (Kim 2014: 141) to re-theorize 
the intersecting space of girlhood and disability as a space of "diversity and belonging" (140). According to Kim,

[a] transnational approach to the human rights of people with disabilities should resist static and timeless generalizations about nation states solely based on their policy implementations; instead make connections among diverse, imaginative, conflicting, and ambiguous self-representations of disabled people around the world (2011: 104).

Reflecting on colonial, neo-colonial, imperialist, and neoliberal ideologies that continue to be reinforced across historically constructed territories including the Global North and South, this issue sheds light on how (able)nationalism and transnationalism have constructed disabled girls using ableist ideologies that individualize and naturalize disability and girlhood. Moreover, as mentioned earlier, every author in this volume (either implicitly or explicitly) has organized her arguments in response to the absent presence of the affective politics of vulnerability as it frames disabled girlhood.

The first two articles in this special volume explore relationships between culture, disability, vulnerability, and the neoliberal ideologies of ablenationalism. We begin with Anastasia Todd's analysis of an HBO documentary film that maps the shifting identities of Alina Hollis, first a disabled orphan in the Southern Ukraine, then a transnational adoptee, and, finally, an allAmerican daughter. Todd offers a critical deconstruction of vulnerable disabled subjectivities by exploring how Alina's storyline (re)secures US exceptionalism through her participation in a beauty pageant for disabled girls that reproduces ableist fantasies of benevolent American excellence. She argues that it is "the affective work of the disabled girl contestants" as embodied by the transnational (disabled) adoptee as "happy object" that is served for the cultural consumption of "the flexible, heteronormative, post-postADA American family." Drawing on a similar trope, Sami Schalk deploys the analytical framework of ablenationalism to explore the representation of disability in the American Girl contemporary line of merchandise "through an analysis of books and doll accessories." Identifying disability as "a literal and metaphoric accessory in the brand," Schalk describes how disability as vulnerable embodiment becomes the "means of touting the superiority, morality, and exceptionalism of the United States."

Shifting the locus of analysis and writing back against hegemonic constructions of disability and girlhood in the Global South, Thuy Nguyen uses participatory visual research as a way of describing the agency and perspective of disabled girls living in Vietnam. Nguyen uses a decolonizing framework that problematizes the universal framing of disability in Western 
discourses by drawing on alternative forms of knowledge produced by disabled girls in a local context. Supporting a similar project of writing against oppressive hierarchies, in this case those of the hearing world, Wendy SmithD'Arezzo and Janine Holc deconstruct the "normative able-bodiedness" in the children's graphic novel, El Deafo written by disabled writer Cece Bell. Drawing on Robert McRuer's framework of "alternative corporealities" (2006: 146), their article uses textual analysis as a way of recognizing the complex identities of Cece (the protagonist in El Deafo) to demonstrate how "disability ... [is] fluid and circulating rather than fixed to a body." This article, along with Nguyen's, employs innovative approaches to foreground the voices of disabled girls in protest against oppressive understandings of vulnerability. Finally, the last article, by Alison Sperling, in this special issue explores a recurrent trope in Carson McCullers' novels of the "freak show performers" who haunt the outskirts of their towns and cause adolescent female protagonists to fear that they will grow into being just like them. Sperling locates her analysis at the intersection of disability studies, freak studies, and queer studies to argue that "the queers, the freaks, the 'deafmutes,' the 'dwarf' and the 'giant,' the drunk, the sick, the half-blind, and... the awkward female adolescent" are not symbolic outcasts but, rather, embody alternative oppositional subjectivities that "[operate] against heteronormative time."

Complementing these oppositional perspectives that refuse the dominant construction of disability as limit without possibility (Titchkosky 2005), the visual essay by Naydene de Lange, Lan Anh Nguyen, and Thu Trang Nghiem provides an account of how dialogues on inclusive education can be fostered through "the power of the visual" to "mak[e] the voices of girls with disabilities heard and their work seen" at various sites. The participation of co-authors who identify as disabled in this visual essay demonstrates a shift from the "traditional researcher-led, academia-based, and top-down models of research" (Goodley and Runswick-Cole 2012: 215) towards grassroots community-based research.

To round out this discussion, we also include a report on girls with disabilities who have become refugees as a result of wars, natural disasters, and human rights violations. In this report, Emma Pearce, Kathryn Paik, and Omar Robles draw on the Women's Refugee Commission's pioneering work that includes "personal narratives collected from girls with disabilities" in its promotion of "humanitarian assistance" as an effort to "[mitigate] the risk of violence, abuse, and exploitation." By demonstrating how "age, gender, and disability influence identity and power in relationships, households, and 
communities affected by crisis," this report provides a set of principles and recommendations for inclusive humanitarian work in ways that recognize the vulnerable situations of adolescent girls with disabilities.

This special issue ends with Nirmala Erevelles's review of Anita Ghai's book, Rethinking Disability in India and Shilpaa Anand's review of the film, Margarita with a Straw. Both reviews foreground radical vulnerability in the articulation of oppositional subjectivities "who express moments of ambivalence, insecurity, and fear but do not cease to communicate their desire, emotions, and strategies for survival in various parts of the planet escaping the binary of global sameness and local difference" (Kim 2011: 102). Together, these contributions unveil the ideologies and practices of exclusion that have been constructed through the political domains of education, humanitarian assistance in the public sphere, and in so doing, demonstrate that we need to reimagine the affective politics of vulnerability in its relation to disabled girls in transnational contexts.

\section{Re-imagining Disability and Girlhood: Where Do We Go from Here?}

We have argued that disability is neither an additive feature in discourses on difference nor a convenient synonym for vulnerability. Rather, we have argued that every article in this special volume critically engages disability as vulnerability discursively and/or materially in ways that disrupt normative notions of girlhood. Some of these articles have even gone so far as to articulate visions that embody radical vulnerability. It is in this context, then, that we ask our readers to reflect on the implications that this conceptualization of disability as radical vulnerability has for girlhood studies in transnational contexts.

We also argue that this discussion on (radical) vulnerability is not all that abstract. Rather, vulnerability in its very concrete form has haunted the very production of this special issue. While we received several proposals for this issue, a number of potential contributors, despite their intent and interest in this themed issue, were unable to meet the assigned deadlines because of illnesses (physical vulnerability). For one of our novice authors, the anxiety of producing publishable work disrupted the writing process so much that even submitting the text was an insurmountable barrier. What we describe here is not peculiar to the publication of this special issue. Rather, we argue here that vulnerability exists as an absent presence even in the 
broader context of knowledge production and dissemination. This repression of (radical) vulnerability is nurtured by the "global economy of knowledge" (Connell 2015:3) where institutions in the Global North prescribe what types of knowledge can be published, what genres and regulations the contributors must follow, which institutions have the authority to produce and circulate this knowledge, and who is intended to make up the valued readership. Each of the above factors, we argue, also creates the conditions for the inclusion and exclusion of (marginalized) communities based on their capacities to mitigate and/or render invisible their vulnerabilities.

As members of academic communities in the Global North who came from the Global South, we have observed and acknowledged the exclusionary practices implicated in this process of knowledge production. We are mindful that we could be more inclusive of scholars and activists from the Global South whose language and ways of writing may be distinctive from normative Western academic discourses. However, even though we attempted to include voices of academics and practitioners from the Global North and South who self-identified as disabled, the challenges of time, resources, and institutional decision-making - the kinds of constraints that we faced in this project-have resulted in gaps, omissions, and silences that prompt the following questions. How would centering radical vulnerability have an impact on knowledge production at the intersections of disability and girlhood studies? What theoretical/methodological approaches can be used to expose practices that exclude, efface, and eradicate discourses of disability as vulnerability from institutional praxis? How will the refusal to read vulnerability as undesirable enable a re-theorization of transgressive subjectivities at the intersection of disability, girlhood, race, and sexuality in the neoliberal contexts of transnational capitalism? What methodological approaches can we use to enable disabled girls to participate in shaping their own spaces and knowledges through more inclusive, reflective, and transformative dialogues?

Notwithstanding the limitations, described earlier, of this issue, we are still hopeful that it has enabled the production of knowledge that engages disability and girlhood studies critically in ways that create a transdisciplinary dialogue among academics, activists, and service providers directed towards social change in the Global North and South. We also hope that the articles in this issue have contributed to the ongoing transnational dialogue about disability, girlhood, and vulnerability in ways that are committed to the struggle to continue to be inclusive of more marginalized communities located in historically colonized spaces in both the Global North and South. 
Thus, rather than ending this guest introduction with a conclusive statement, we invite readers to reflect on these questions and aspirations that we have just raised. We hope that this special issue opens up new facets of critical thought and transformative action that engages girlhood from the critical standpoints of radical vulnerability and disability studies.

$\cos$

Nirmala Erevelles is a Professor of Social and Cultural Studies in Education at the University of Alabama. Her research focuses on the unruly, messy, unpredictable, and taboo body in the intersecting areas of disability studies, critical race theory, transnational feminism, sociology of education, and postcolonial studies. She is the author of Disability and Difference in Global Contexts: Towards a Transformative Body Politic (2012).

Xuan Thuy NguYen is an adjunct professor in the Critical Disability Studies program at York University and the Faculty of Education at Mount Saint Vincent University, Canada. She is the author of The Journey to Inclusion (2015) and is the Principal Investigator of the project, Monitoring Educational Rights for Girls with Disabilities in Vietnam.

\section{Acknowledgements}

We are grateful to Claudia Mitchell for giving us the opportunity to work on this special issue and for her invaluable advice and suggestions. We would also like to express heartfelt gratitude to the contributors to this special issue as well as to all the reviewers who were willing to do some of the most important work of this issue anonymously. And, finally, we wish to thank Ann Smith for her thorough and meticulous editing.

\section{Notes}

1. http://www.dawncanada.net/main/wp-content/uploads/2014/03/English-ViolenceJanuary-2014.pdf

2. http://www.ungei.org/infobycountry/files/EAP_UNGEI_Newsletter_May_2013_ Disabilities.pdf

3. http://www.gpcwd.org/

4. http://www.globalpartnership.org/

5. http://www.riglobal.org/sustainable-development-goals-disability-inclusion-indevelopment/ 


\section{References}

Alexander, M. Jacqui, and Chandra T. Mohanty. 2010. "Cartographies of Knowledge and Power: Transnational Feminism as Radical Praxis.” Pp. 23-45 in Critical Transnational Feminist Praxis, ed. Amanda Lock Swarr and Richa Nagar. New York: SUNY Press.

Aapola, Sinikka, Marnina Gonick, and Anita Harris. 2005. Young Femininity: Girlhood, Power and Social Change. New York: Palgrave Macmillan. Beazley, Sarah, ed. 2014. Childhood and Disability: Key Papers from Disability \& Society. London: Routledge.

Connell, Raewyn. 2015. "Social Science on a World Scale: Connecting the Pages." Sociologies in Dialogue 1, no. 1:1-16.

Disabled Women's Network of Canada. n.d.

http://www.dawncanada.net/main/wp-content/uploads/2014/03/EnglishViolence-January-2014.pdf (accessed 27 December 2015).

Erevelles, Nirmala. 2011. Disability and Difference in Global Contexts: Enabling a Transformative Body Politic. New York: Palgrave Macmillan Erevelles, Nirmala, and Kagendo Mutua. 2005. “'I Am a Woman Now!

Rewriting Cartographies of Girlhood from the Critical Standpoint of Disability.” Pp. 253-269 in Geographies of Girlhood: Identities In-between, ed. Pamela J. Bettis and Natalie J. Adams. New York: Routledge.

Ferri, Beth A., and David J. Connor. 2010. "I Was the Special Ed. Girl': Urban Working-class Young Women of Colour." Gender and Education 22, no. 1: 105-121.

Frohmader, Carolyn, and Helen Meekosha. 2012. "Recognition, Respect and Rights: Women with Disabilities in a Globalised World.” Pp. 287-307 in Disability and Social Theory: New Developments and Directions, ed. Dan Goodley, Bill Hughes and Lennard Davis. Houndmills: Palgrave Macmillan. Gannon, Susanne, and Marnina Gonick (2014). “Choir Practice' in Three Movements: Analyzing a Story of Girlhood through Deleuze, Butler, and Foucault." Pp. 19-39 in Becoming Girl: Collective Biography and the Production of Girlhood, ed. Marnina Gonick and Susanne Gannon. Toronto: Women's Press.

Gilmore, Leigh, and Elizabeth Marshall. 2010. "Girls in Crisis: Rescue and Transnational Feminist Autobiographical Resistance.” Feminist Studies 36, no 3: 667-690.

Global Partnership on Children with Disabilities. n.d.. http://www.gpcwd.org/ (accessed 25 December 2015).

Global Partnership for Education. n.d.. http://www.globalpartnership.org/ (accessed 12 December 2015).

Gonick, Marnina. 2006. "Between 'Girl Power' and 'Reviving Ophelia' Constituting the Neoliberal Girl Subject.” NWSA Journal 18, no. 2: 1-23. 
Goggin, Gerard. 2009. "Disability, Media, and the Politics of Vulnerability." Asia Pacific Media Educator 1, no. 19: 1-13.

Goodley, Dan, and Katherine Runswick-Cole. 2012. "Decolonizing

Methodology." Pp. 215-232 in Inclusive Communities, ed. Andrew Azzopardi and Shaun Grech. Rotterdam: Sense.

Hastings, Elizabeth. 1997. "Assumption, Expectation and Discrimination: Gender Issues for Girls with

Disabilities." https://www.humanrights.gov.au/news/speeches/gender-issuesgirls-disabilities (accessed 3 December 2015).

Human Rights Watch. 2012. Human Rights of Women and Children with Disabilities. https://www.hrw.org/sites/default/files/related_material/0912_ disabilities_brochure_0.pdf (accessed 10 September 2014).

Jennings, Sheila K. 2013. "Reflections on Personhood: Girls with Severe Disabilities and the Law." Canadian Journal of Disability Studies 2, no. 3: 55-97. Jarman, Michelle. 2005. "Resisting 'Good Imperialism': Reading Disability as Radical Vulnerability." Atenea 25, no. 1: 107-116.

Kim, Eunjung. 2011. "'Heaven for Disabled People': Nationalism and International Human Rights Imagery.” Disability \& Society 26, no. 1: 93-106. Kim, Eunjung. 2014. "The Spectre of Vulnerability and Disabled Bodies in Protest." Pp. 137-154 in Disability, Human Rights and the Limits of Humanitarianism, ed. Michael Gill and Cathy Schlund-Vials. Farnham: Ashgate.

Leonard Cheshire Disability. 2014. "Realising the Rights of Women and Girls with Disabilities."

http://www.leonardcheshire.org/sites/default/files/Women_and_girls_with_dis abilities_0.pdf (accessed 3 December 2015).

Nguyen, Xuan Thuy. 2015. The Journey to Inclusion. Rotterdam: Sense.

Ortoleva, Stephanie, and Hope Lewis. 2012. "Forgotten Sisters - a Report on Violence against Women with Disabilities: An Overview of its Nature, Scope, Causes and Consequences." Northeastern University School of Law Research Paper. http://www.panusp.org/wp-content/uploads/2013/02/ForgottenSisters-2012.pdf (accessed 8 September 2014).

Pothier, Dianne, and Richard Devlin. 2006. Critical Disability Theory: Essays in Philosophy, Politics, Policy, and Law. Vancouver: University of British Columbia Press.

Pinto, Paula. 2011. "Monitoring Human Rights: A Holistic Approach.” Pp. 451477 in Critical Perspectives on Human Rights and Disability Law, ed. Marcia Rioux, Lee Ann Basser and Melinda Jones. Leiden: Martinus Nijhoff Publishers.

Rehabilitation International (n.d.). Sustainable Development Goals: Disability Inclusion in Development. http://www.riglobal.org/sustainable-developmentgoals-disability-inclusion-in-development/ (accessed 7 December 2015). 
Rentschler, Carrie A., and Claudia Mitchell. 2014. "The Re-description of Girls in Crisis." Girlhood Studies 7, no. 1: 2-7.

Rioux, Marcia, and Lora Patton. 2011. "Beyond Legal Smoke Screen: Applying a Human Rights Analysis to Sterilization Jurisprudence." Pp. 242-271 in Critical Perspectives on Human Rights and Disability Law, ed. Marcia Rioux, Lee Ann Basser and Melinda Jones. Leiden: Martinus Nijhoff Publishers.

Rousso, Harilyn. 2003. "Education for All: A Gender and Disability Perspective." Background paper prepared for the Education for All Global Monitoring Report 2003/4 Gender and Education for All: The Leap to Equality. http://unesdoc.unesco.org/images/0014/001469/146931e.pdf (accessed 5 September, 2013).

Stienstra, Deborah. 2015. "Trumping All? Disability and Girlhood Studies." Girlhood Studies 8, no. 2: 54-70.

Titchkosky, Tanya. 2005). "Disability in the News: A Reconsideration of Reading." Disability \& Society 20, no. 6: 653-666.

United Nations. 2006. Convention on the Rights of Persons with Disabilities (UNCRPD). http://www.un.org/disabilities/convention/conventionfull.shtml (accessed 10 April 2012).

United Nations Educational, Scientific and Cultural Organization (UNESCO). 2003. Gender and Education for All: The Leap to Equality. EFA Global Monitoring Report 2003/2004. http://www.unesco.org/education/efa_report/ summary_en.pdf (accessed 12 December 2012)

United Nations Girls' Education Initiative (UNGEI). 2013. Achieving Gender Equality in Education for All Children with Disabilities. http://www.ungei.org/ infobycountry/files/EAP_UNGEI_Newsletter_May_2013_Disabilities.pdf (accessed 11 November 2015). 